\title{
The study of urban climate and traffic: Considerations from the Araraquara case, SP
}

\author{
Clélia Mendonça de Moraes ${ }^{1, *}$, Edson Melanda ${ }^{2}$, and Nilson Roberto de Barros Carneiro ${ }^{1}$ \\ ${ }^{1}$ PMA Prefeitura Municipal de Araraquara, Coordenadoria de Mobilidade Urbana, Araraquara,SP, Brasil \\ ${ }^{2}$ UFSCar Univesidade Federal de São Carlos, São Carlos, SP, Brasil
}

\begin{abstract}
The article discusses the interface between the influence of the urban climate and the traffic accident, there are as reference the results of the research carried out for the Araraquara case, SP, Brazil. Initially presented a brief analysis of urban mobility, geoprocessing (GIS) and the climatic importance in relation to urban sustainability. The article analyzes the urban climate of Araraquara, especially with regard to solar radiation on city streets and green areas. It was based on the premise that there is a correlation between the urban microclimates and the variables related to the traffic accident. Thus, a georeferenced mapping of the urban geometry was carried out by associating the climatic variables such as solar radiation, temperature and humidity of the air, to three parameters related to the traffic accident were chosen from the a) traffic accident with victim, b) without victim and c) motorcycle. At the end, the article proposes how the results found can reduce traffic accident and contribute to urban planning
\end{abstract}

\section{Introduction}

The United Nations has coordinated global efforts for the Action for Traffic Safety 2011-2020, in which governments around the world are committed to take new measures to prevent traffic accidents, which kill about 1.3 million people per year. [15] In May 2012, the UN General Assembly, through a resolution, reinforced a request for Member States and other interested actors to engage in the actions of the Decade. [15]

In Brazil, an effort has been made through the São Paulo Movement of Traffic Safety (Infosiga) - a government program of the State of São Paulo (SP), which aims to reduce by the half the number of traffic deaths until 2020 - registered a decrease of $4,8 \%$ in fatalities due to accidents throughout all the State, in the first quarter of 2017. The data reinforce the reduction trend already verified throughout the year 2016, when there was a decrease of 5.6\% compared to 2015. (SP_19 / 04/2017) [16] According to Infosiga-SP, there was a decrease of $4.8 \%$ compared to the first quarter of 2016. Men and young people lead the statistics.

One of the factors that contributed to the reduction of traffic accidents were urban mobility interventions. The relationship between traffic accidents and urban mobility is an attribute of cities and refers to the ease of movement of people and goods in urban space defined from transportation planning to urban planning, highlighting the aspects of the built environment in search of the quality of life of the city. Urban interventions should consider the diversity of urban design and density of land use, distance to the transport system and accessible destinations, or dimensions of the environment built as density, linked to good transport systems with the aim of promoting sustainable mobility. Subject that receives more attention and special interest from all government authorities.

However, there is a large gap - of knowledge and understanding - between environmental behavior and climate dynamics (radiation, rainfall, heat emission, influence on air circulation) that are responsible for the movement of vehicles and pedestrians on city streets. [11] [14].

Cities that consider the policies related to the integration between mobility and urban sustainability ensure greater efficiency and dynamism of urban functions, with greater and better circulation of people and goods. This is reflected in the valorization of the public space, in the sustainability and in the development of the city, reconciling the environmental, social and economic dimensions. [7]

In this research was studied a methodology of environmental evaluation of traffic accident for urban areas, it was tried to identify the places and their respective factors and generate greater accident occurrence with the use of a geoprocessing tool QGIS; allows the identification of spatialisation of accidents and the generation of products, such as thematic maps produced, which are very important tools, making it possible to investigate the causes and make decisions to prevent future occurrences.

* Corresponding author: arqclelia@hotmail.com 
From these traffic accident maps constructed with the QGIS, it was identified the climatic parameters, responsible for the increase in the number of traffic accidents. It allows reflecting on the various dimensions of sustainability as well as highlighting the importance of environmental assessment in the urban climate and also considering the social and economic aspects related to the prevention of the number of traffic accident occurrences.

\subsection{Urban Mobility, GIS and Climatology}

\subsubsection{Urban Mobility and Traffic Accidents}

According to the Ministry of Cities [8], urban mobility is defined as an attribute of cities that refers to the ownership of displacements of people and goods in urban space. The urban displacement is carried out through vehicles, roads, sidewalks and involves all the infrastructure that enables people to come and go. According to what a certain area develops, there must be adequate means and infrastructure that promote the sufficient displacement of goods and people [9].

Urban mobility plans for Brazilian cities can be carried out using tools for diagnosis and guidance. One of these tools is Federal Law No. 12,587 / 2012, known as the "Mobility Law" [8]. This law regulates the management of mobility policy in Brazilian cities. According to this law, it is possible to define principles and guidelines compatible with the concepts of sustainable urban mobility, making mandatory the elaboration of an Urban Mobility Plan, integrated and compatible with the respective master plans or inserted therein, for approximately 3,065 municipalities (more than 55\% of all Brazilian municipalities). The law also establishes the need for a systematic evaluation, revision and updating of the Mobility Plans, making it essential as a tool to evaluate and control the mobility conditions in the municipalities.

Public agencies are aware of the problems faced by most Brazilian cities about urban mobility that suffer from (1) indiscriminate use of cars, (2) increased congestion, (3) energy consumption and noise generated in the transportation sector, (4) urban climate .

In this way, the data of the indicators of the planning of the road system must be adjusted, considering the knowledge of the technical team that carries out the study, to better reflect the local conditions. In this respect, the planner's view of the city's urban network will allow the detection of road systems that develop particular dynamics with the interurban space that are influenced by climatic conditions, which when not observed cause accidents or trampling of people and / or animals . Traffic accidents like any harmful event that involves the vehicle, the road, the man currently causes a large amount of lives to be lost annually.

\subsubsection{Geographic Information System (GIS)}

The term Geographic Information System (GIS) and its synonym Geographic Information System used in North
America is often applied to geographically oriented computing technology, integrated systems used in substantive applications, and more recently a new discipline that is generating great interest worldwide. [3] Every day, in different parts of the world, people ask questions like these: Climatologist: "How has the hole in the ozone layer changed in the last 10 years"? Planner: "How has the distribution of urban and rural population changed between the last two censuses"? [4] All these questions and many others similar to them are related to patterns and geographic processes on the Earth's surface. As professionals in these fields know very well, answering these questions requires access to geographic information that is characterized by its multidimensional nature. ( $\mathrm{x}, \mathrm{y}, \mathrm{z}$ coordinates and time), its large volume and high processing cost. The architectural design of a building may present geographical problems, such as in disaster management, but only on a very detailed or local scale. The information required for the provision of the building is also local - the size and shape of the plot, the vertical and underground extension of the building, the slope of the building and its accessibility using normal and emergency infrastructures. The global spread of the SARS epidemic in 2003 from avian influenza in 2004 was a much broader and more widespread problem involving information on entire national populations and global transport patterns. Data, information, evidence, knowledge, wisdom, compose an information systems which help us manage what we know, facilitating organization and storage, access and retrieval, manipulation and synthesis and the application of knowledge to problem solving. [4]

The GIS solves an old problem of general scientific knowledge with specific information resulting in a practical value to both. In this research the geographic problems of traffic accidents with / without victim and motorcycle are verified. Facts that occur in many parts of Brazil and other countries.

Geographically Brazil is formed by tropical regions, where is common the abrupt climatic changes caused by the displacement of air masses, that is, the entrance of frontal systems that alter the perception of the sensation of thermal comfort by the individual.

In order to demonstrate this fact, it was investigated the mapping of traffic accidents, classified in occurrences with and without victim and motorcycle from predefined symbols in the urban configuration of the city of Araraquara and identifying through the meteorological station of INPE and the Secretariat Security through the Civil Defense and the Urban Mobility Coordination through the action of the Traffic Agents.

\subsubsection{Climatological importance related to urban sustainability}

> The influence of climatology on the behavior of the inhabitants of a city. 
The current climatic problems are due to environmental factors, the individual identifies the effects of atmospheric environments which, in turn, depend on age, social group, culture and experiences among other factors. This study evaluated the perception of the weather and climate conditions of the inhabitants of the medium size city of Araraquara, SP. It is important to emphasize that this city is located in Brazil, known as a country with tropical climate, presents diverse climatic characteristics in its various regions.

The behavior of the inhabitant of the city is influenced by the human thermal comfort also depends on sociocultural factors, that is, the patterns of thermal comfort vary according to the adaptation of the individual to his environment. For example, people living in hot climate regions in Brazil are more adapted to heat and are less cold tolerant; and the same happens with those who live in colder regions, which are less heat tolerant and more adapted to the cold. [11]

\section{$>$ How weather factors can influence urban mobility.}

The climatology will influence the habits of the human being, in the form of the building or in the urban climate, as well as in the local culture. Today, there is a growing public interest in the quality of urban spaces in cities, which contributes to the quality of life of the population. Thus, knowledge of climatic factors such as visible solar radiation, relative air temperature and humidity, atmospheric pressure, winds, cloudiness, precipitation and favors the occurrence of islands of heat, fog, dust domus and thermal inversion. These factors influence the characteristics of the site, such as morphology, presence of vegetation, bodies of water, which makes it essential to develop urban guidelines that aim at better climatic conditions in cities. Mainly due to the intense growth of urban areas, on rural areas, they demonstrate the environmental problems that most impact the territories. [14].

There is an interrelation between climatic parameters and the special organization of cities. The heat exchanges between the body and its environment are influenced by external meteorological parameters such as temperature, humidity, air velocity, radiation directly affect the behavior of the human being allowing or not the dissipation of excess heat from the body. The external climatic factors also influence the feeding of the local population, the type of clothing, the behavior of the people, the pathologies, the air pollution, etc.

The researchers studied the cylinder models represented by the human body were Fanger, (1970), Gagge et al. (1971), Wyndham; Atkins apud Hwang; Kong (1977) and Ferreira (1997). They all incorporate basic characteristics such as heat transfer between blood and tissue, conduction in the tissues, respiration, convection, radiation and evaporation. By means of simplified models such as these, it is possible to evaluate global conditions of thermal comfort, to perform studies on the physiology of the human body, as well as to evaluate the effect of variation of thermal properties and physiological parameters on the results of the human body thermal model.

In this aspect, several researches on the sensation of human thermal comfort and the climatic conditions in tropical climate; however, there is a lack of investigations into the pre-frontal inputs that alter the individual's perception and the thermal behavior of the materials. The climate causes significant variations in human metabolism. With the entry of air mass (prefrontal) the change of the heat transfer in the human body and in the model of the thermal system of the human body occurs. This is because external climatic factors also influence the perception of the individual due to the pre-frontal inputs. A pre-frontal is the day of air mass advance, when there is overheating and greater air dryness, or atmospheric pressure drop, or change in the direction of prevailing winds, among other changes, such as cloudiness, which also changes. This advance of air mass occurs in two stages: 1) Pre, which corresponds to the Pre-F: foreshadow and advance, and 2) PostFrontal in Post-F: domain and transition and at that moment begins the tropicalization of the Polar mass. As an example, on a winter day, air may enter a hot mass, and individuals begin to feel warmth and some individuals report that feeling of malaise [11], then a repeated rain occurs and then the temperature returns to normalize. This factor can also occur during the summer. Such factors affect urban mobility as the driver experiences drowsiness and malaise when driving mainly on the roads and with the sudden rain traffic accidents occur due to the traffic of the vehicles. According to reports of insurance companies [11] by car the days of pre-frontal corresponds to the days where there are higher incidences of traffic accidents and consequently assistance to the insured.

\section{> The importance of using qgis tool to identify locations where climatic influences can cause traffic accidents.}

Quantum GIS (QGIS) is a software for Geographic Information Systems (GIS) in the most diverse formats. This system was used for the development of a thematic map of traffic accidents occurred in the year 2016, 2017 and 2018, in the city of Araraquara - SP. This solution begins with the extraction of accident data provided by the 13th Battalion of the Military Police of the State of São Paulo - SP and the inclusion of this data in a database in PostgreSQL; then the georeferencing is performed in the urban configuration of Araraquara in PostGIS, and finally the thematic map is created through Quantum GIS.

Traffic accidents occur at a multiplicity of causes. The literature addresses this question in different ways; however, in general, the factors associated with an accident can be met in up to three major categories. a) Factors related to man; b) Factors related to the type of vehicle; c) Factors related to the environment (including traffic and road design). [14] 
Environmental and road factors include visual obstructions, slippery roads (wet, snowy, etc.), transient hazards (road works, objects on the road), and road design problems [8]. According to Chagas (2011) [9], it determines some other factors, including damaged pavement, inadequate or erased road signs, adverse climatic conditions, etc. The QGIS software allows the production of maps showing the spatial distribution of accidents in the city, neighborhoods and roads most affected from the data obtained in the report card.

In this research were produced in the QGIS maps showing the spatial distribution of accidents in the city, the neighborhoods and the most affected roads in the city, and from these, it was identified the accidents occurred in the year, in the neighborhoods and roads with higher incidence. The products generated are demonstrated in the form of thematic maps and can thus investigate causes and decision making to prevent future occurrences.

For Gold (1998), the identification of the causes of accidents is a requirement for the adoption of preventive measures that reduce their incidence and severity. However, for this, it is fundamental to spatialize the occurrences, identifying the sites with the highest accident rate to investigate the causes and apply actions locally, allowing the prevention of new occurrences, which would represent both social and economic gain. According to Zanotelli and Coutinho (2003, apud Bernardino, 2007), spatial representation provides a synthetic and analytical reading of the phenomenon and, through association and comparison between the different places, it is possible to understand the causes of socio-spatial differentiation of events.

\subsection{Objectives and justifications}

The objective is to verify the correlation between the urban microclimates and the variables related to the traffic accident. Thus, a georeferenced mapping of the urban geometry was carried out associating the climatic variables such as solar radiation, temperature and humidity of the air, to three parameters related to the traffic accident, chosen from the a) traffic accident with victim, b) without victim and c) motorcycle.

\section{Methodological Summary}

a) In alignment with the objectives of the discussion work on the interface of the influence of the urban climate, traffic accidents occur within the reality of Brazilian urban mobility. Identifying the functioning of the relation between the configuration of the cities space and the climatic relations that surround them. A multidisciplinary approach is possible through special georeferenced analysis, involving several areas of knowledge. We identified facilities and restrictions of its applicability, the development of the applied study was divided into two major phases:

b) a) Data collection with the Bulletins of Occurrence of the 13th Battalion of the Military Police of the State of São Paulo on traffic accidents occurred with / without victim and motorcycle in the years 2016-2018

c) b) Information on the weather conditions of the city of Araraquara;

d) c) Identification of traffic accidents with the georeferenced tool of QGIS software verifying the streets and avenues in the distribution of movements in the urban road network.

\section{Discussions and Results}

\section{a) Data collection in Figure 1 and 2}

Figure 1 shows the total number of traffic accidents with victims that occurred during the months of 2016, 2017 and 2018. It is noted that there are several factors that influence traffic accidents, but when it is observed under the weather aspect as in Fig. 3, frontal system input, it is observed that in the months of June, July and August, where there is a greater occurrence of frontal precock, it coincides with a greater number of traffic accidents with victims. This occurs due to the strong heat that occurs three days before and after there is a very strong rain that influences the driver's thermal metabolism and comfort. This same fact occurs with Fig. 2, where in the months of June, July and August there is a greater accident with motorcycle victims.

b) Information on the weather conditions of the city of Araraquara; Figure 3 and 5.

In the item, a special analysis of the traffic accidents with / without victim and motorcycle was carried out in the mapping of the city of Araraquara from the years 2016, 2017 and 2018. It can be observed that Maria Antonia Camargo de Oliveira Avenue and the central region present greater number of traffic accidents. In this map, also, presents a layer of air temperature and traffic accidents and in the places it is verified where there is a higher temperature; there is a greater number of traffic accidents. 


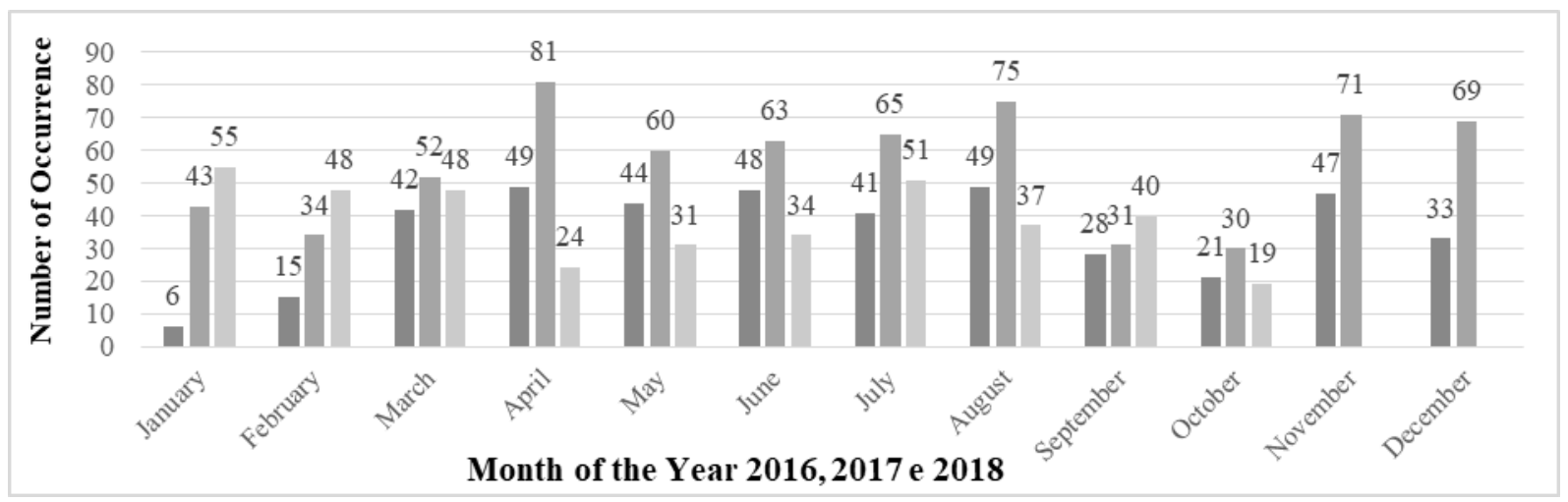

Fig. 1. Traffic Accident With Vitim 2016_2017 and 2018

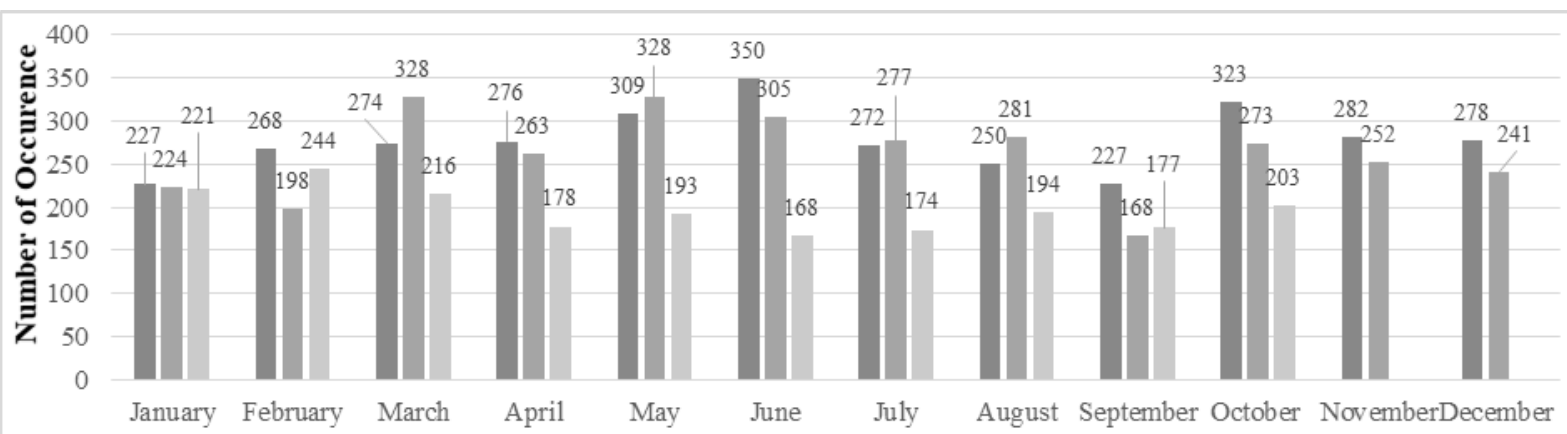

Months of the Year 2016 - 2017 - 2018

Fig. 2. Traffic Accident No Vitim 2016 2017 and 2018

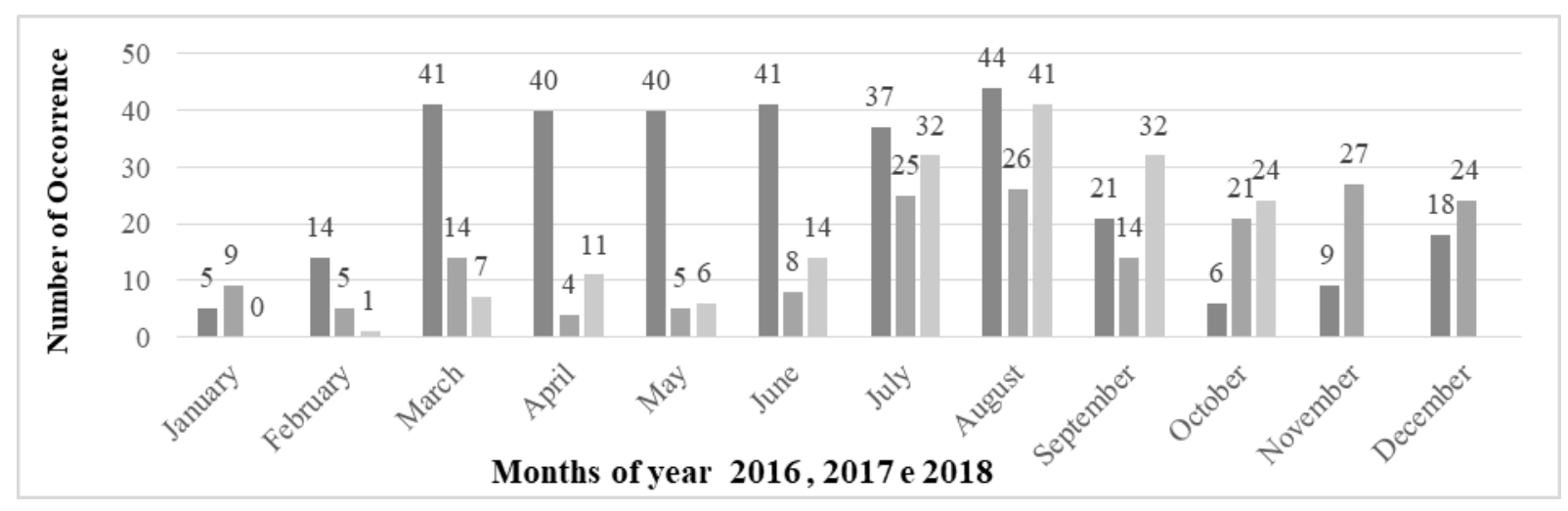

Fig. 3. Traffic Accident with Motorcycle 2016, 2017 and 2018

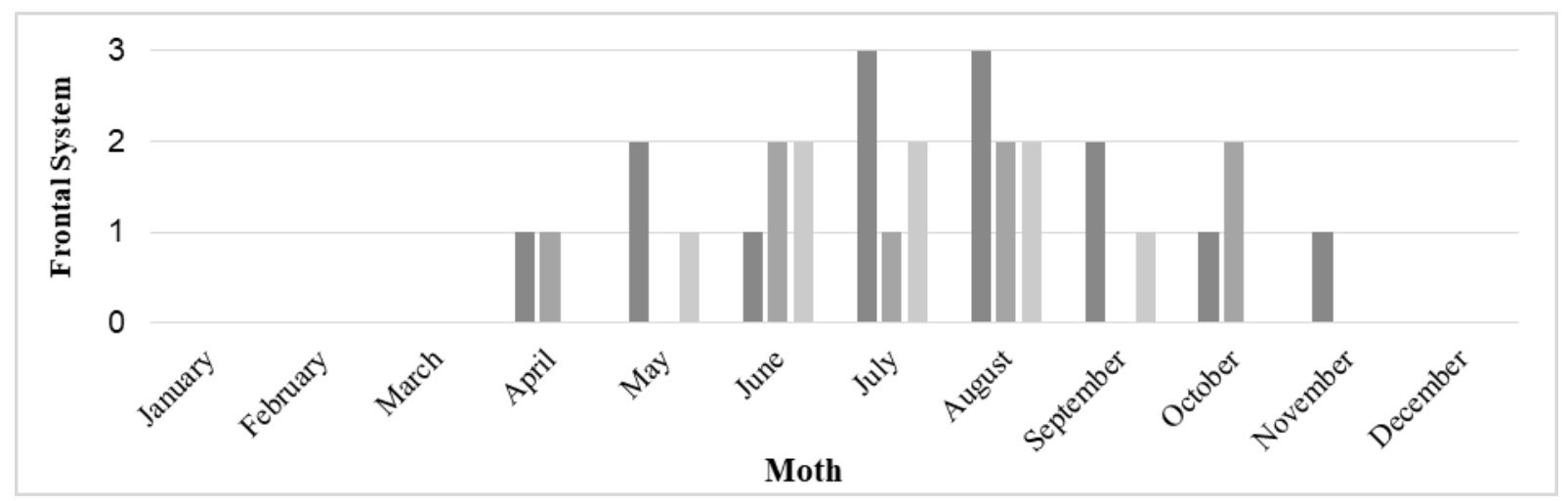

Fig. 4. Frontal System 2016, 2017 and 2018 
a) Identification of traffic accidents with the georeferenced tool of QGIS software verifying the streets and avenues in the distribution of movements in the urban road network. Figure 4, 5 and 6.



Fig. 5. Kernel Density Map

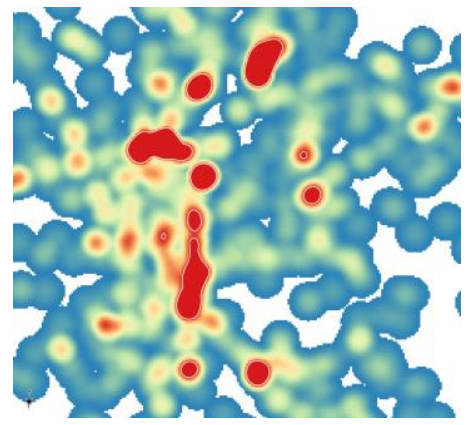

Fig. 6. Air temperature map according to the largest number of vehicle accidents

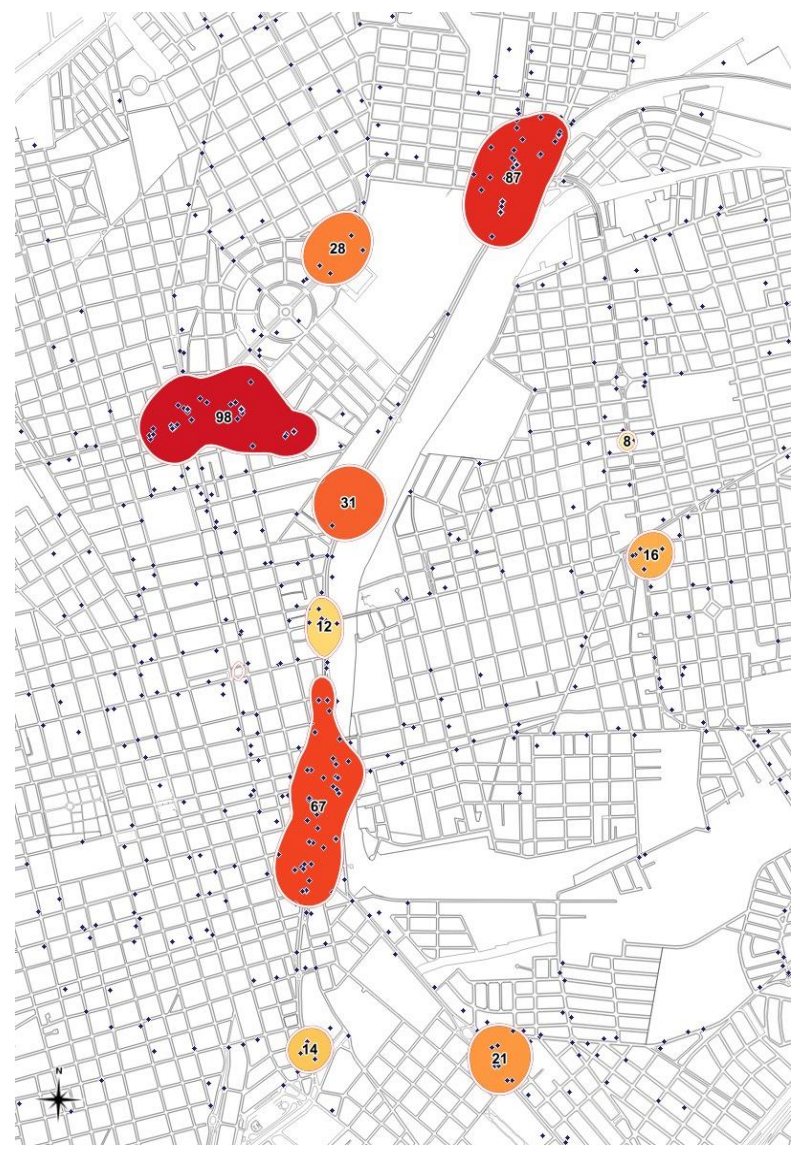

Fig. 7. Occurrence points with the highest traffic accident rate

\section{Final considerations}

The present study showed that the QGIS software is a tool that allows the formation of thematic maps of spatial analysis in the field of urban mobility, allowing the design of an urban space in the field of sustainability. The analysis of the traffic accident data already allows us to know a little about the city's traffic reality and in this work it was possible to identify the areas, mainly the neighborhoods and the roads, where these are more recurrent the influences of the climatic conditions cause accidents of transit on days where there is abrupt climate change, such as rainfall. The spatialisation of accidents and the generation of products from there, as thematic maps are tools of great importance to act in a targeted way, making possible causes investigation and decisionmaking. The criteria used for the distribution of the climatic variables, according to the meteorological forecast, showed that the climatic behavior was made taking into account the atmospheric dynamics, based on the displacements of the prefrontal and its relations with the tropical masses in the seasons.

The result of the work shows that the data on traffic accidents are part of a theoretical and methodological proposal to support and justify the work of urban mobility and urban climatology, it and can be named Climate Urban Transport System (C.U.T.S.). The map of Figure 6 shows the map of air temperature 
according to the largest number of accidents with vehicles, which allows to study the thermal comfort and treat the thermodynamic components of the climate in an integrated way. Air quality analysis can also be performed by verifying the number of vehicles circulating in the city and raising air conditions in the urban environment. The meteorological impact caused by the entrance of pre-frontal reaches climatic phenomena like rains and elevated temperatures that alter the perception of the individual when reaching high intensities, showing by the presented data that they are able to compromise the physical and social integrity of the city and disrupting the city's transportation system.

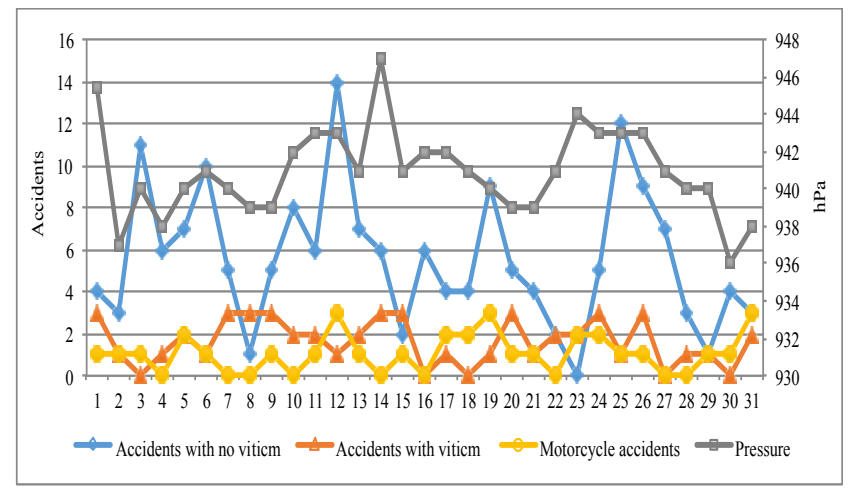

Fig. 8. Occurrence of accidents

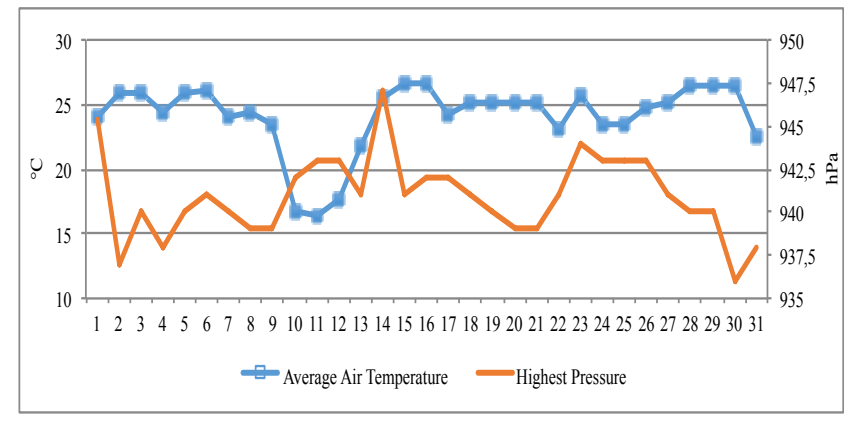

Fig. 9. Relation between air temperature and pressure.

The QGIS software also allows identifying the heat islands. When identified, it allows the joint of the spacetime representation of the city's atmosphere. By identifying the heat islands, the air temperature and the entrance of frontal systems came to be the main climatic element explored in the work. Defining the behavior of the changes provided in the balance of abrupt changes of the climate and to the complete of the urban site of the city of Araraquara - SP, constrasting the close relationship with the type of land use and occupation. The identification of the climatic situation of the city related to the number of occurrences of traffic accidents with / without victim and motorcycle allows the public agency to identify the points of greatest conflict of traffic accident located in the city. It allows proposing decisionmaking in order to avoid traffic accidents, such as the engineering sector, to carry out traffic engineering projects, to improve city signaling, deployment and time control of traffic lights, street bump, and other occasional transport measures. As well as working with traffic education advertising, alert for drivers and pedestrians about when the frontal system inputs to the individual to be aware and thus be taking preventive measures to avoid traffic accidents. This work focuses on the city and, in the future, is expected to encompass all of the country's highways, due to the ease of allowing these changes.

\section{Acknowledgment}

City Hall of the city of Araraquara, Federal University of São Carlos, 13th Battalion of the Military Police of the State of São Paulo .

\section{References}

1. Brito, A. S. L. e Lima, D. Urban mobility and sustainable planning in the municipality of resende: Exploratory case study. Scientific article, 2017

2. FOTHERINGHAM, A. Stewart; BRUNSDON, Chris; Charlton, Martin Geographically Weighted Regression: the analysis of spatially varying relationships. John Wiley \& Sons, LTD. San Francisco, USA, 2010 ISBN 978-0471-49616-8

3. Longley, P.A .; Goodchild, M.F .; Maguire, D.J.; Rhind D. W., 2005 Geographical Information Systems: Principles, Techniques, Management, and Applications. Second Edition, Abridged. editor Wiley John Wiley \& Sons, Inc. , New Jersey, Canada, 2005 ISBN13:978-0-471-73545-8 and ISBN-10:0-47173545-0

4. Longley, P.A.; Goodchild, M.F.; Maguire, D.J. and Rhind, D.W., Geographical Information Systems and Science. Second Edition. John Wiley \& Sons, ltd. England. 2006

5. Maguire, D.; Goodchild, M.F. e Rhind, D., Geographical Information Systems: Principles and Applications, Longman Schientific \& Technical: Copublished in the United States and Canada with John Wiley \& Sons, Inc., New York. EUA. Volume 1, 1991, ISBN 0-582-05661-6

6. Maguire, D.; Goodchild, M.F. e Rhind, D. Geographical Information Systems: Principles and Applications, Longman Schientific \& Technical: Copublished in the United States and Canada with John Wiley \& Sons, Inc., New York. EUA. Volume 2, 1991, ISBN 0-582-05661-6

7. Magagnin, R.C.; Rodrigues, A.N.S.(2008) TRANSPORTES, v. XVI, n. 1, p. 25-35, june/ 2008.https://www.revistatransportes.org.br/anpe t/article/view/13

8. Ministry of Cities and IBAM (2004) Mobility and Urban Policy: Grants for Integrated 
Management. Available on:

http://www.cidades.gov.br/media/Mobilidade e Politica Urbana.pdf

9. Ministry of Cities; IBAM (Brazil). Federative Republic of Brazil. Mobility and urban policy: subsidies for integrated management. Rio de Janeiro, 2005. Agreement no. 7/2004.

10. Ministry of Cities (2006). Course Integrated Management of Urban Mobility. Module I: National Policy on Urban Mobility. Ministry of Cities, National Program for Capacitation of Cities, Brasília, March 2006. Available on: http://www.cidades.gov.br/CursoSemob/modul os.html

11. Moraes, Clélia Mendonça de. Thermal comfort in classrooms in Brazil: experimental and numerical analysis -Campinas, SP: 2009.

12. Rizzon, B.M. Prevalence of factors associated to the occurrence of traffic accidents in the surroundings of exclusive tracks for buses in contra flow. Department of Civil Engineering, School of Engineering, Federal University of Rio Grande do Sul. Porto Alegre, 2017.

13. Oliveira, G.M.; Rodrigues da Silva, A.N. Challenges and prospects for evaluation and improvement of sustainable urban mobility: a comparative study of Brazilian municipalities. Transportation v. 23, n. 1 (2015), p. 59-68.

14. Schutzer, J.G. - Strategic analysis of topography and urban land planning: structuring environmental compartments in macro-metropolis of São Paulo. Revista LABVERDE - Laboratório Verde vol 1. N॰5 FAU/USP Dezembro, 2012. ISSN: 2179-2275.

15. https://nacoesunidas.org/campanha/segurancatransito/

16. http://www.infosiga.sp.gov.br/

17. http://www.inpe.br/

18. http://araraquara.sp.gov.br

19. MENDONÇA, F.; MONTEIRO, C.A.F., Urban Climate, São Paulo, Context 2002. Geografares Magazine, $\mathrm{n}^{\circ} 10$, p08-16, 2012, February, ISSN 2175-370 Alves, R.S. , Filano, E.S. http://periodicos.ufes.br/geografares/article/vie wFile/1721/1700 